J. vet. Pharmacol. Therap. 31, 108-116, doi: 10.1111/j.1365-2885.2007.00936.x.

\title{
Comparative pharmacokinetics of two intravenous administration regimens of tiludronate in healthy adult horses and effects on the bone resorption marker CTX-1
}

\section{DELGUSTE* \\ H. AMORY* \\ J. GUYONNET ${ }^{\dagger}$ \\ D. THIBAUD ${ }^{\dagger}$ \\ P. GARNERO* \\ J. DETILLEUX* \\ O. M. $\operatorname{LEPAGE}^{\S} \&$ \\ M. DOUCET}

*Department of Clinical Sciences, Faculty of Veterinary Medicine, University of Liege, Liege, Belgium; ${ }^{\dagger} \mathrm{CEVA}$ Santé Animale, Libourne Cedex, France; ${ }^{\ddagger}$ INSERM research unit 664 and Synarc, Lyon, France;

${ }^{\S}$ Département Hippique, Ecole Nationale Vétérinaire de Lyon, Université de Lyon, Marcy L'Etoile, France; 'Département de biomédecine vétérinaire, Faculté de médecine vétérinaire, Université de Montréal,

Montréal, QC, Canada
Delguste, C., Amory, H., Guyonnet, J., Thibaud, D., Garnero, P., Detilleux, J., Lepage, O. M., Doucet, M. Comparative pharmacokinetics of two intravenous administration regimens of tiludronate in healthy adult horses and effects on the bone resorption marker CTX-1. J. vet. Pharmacol. Therap. 31, 108-116.

Bioavailability and pharmacological effects of tiludronate were compared when administered as an intravenous (i.v.) bolus at a dosage of $0.1 \mathrm{mg} / \mathrm{kg}$ body weight (b.w.) once daily for 10 consecutive days (group $1, n=6$ ) and as a single constant rate infusion (CRI) at a total dose of $1 \mathrm{mg} / \mathrm{kg}$ b.w. (group 2, $n=6$ ) in healthy adult horses.

Tiludronate and carboxy-terminal cross-linking telopeptide of type I collagen (CTX-1) were measured in plasma and urine.

There was no statistically significant difference in area under the curve (AUC) and clearance $(\mathrm{Cl})$ between the two groups. Bioavailability of the CRI was $103 \%$ (not significantly different) that of the 10 daily i.v. bolus doses. Cumulative urine tiludronate excretion could not be compared between groups because of poor sensitivity of the assay in urine. Plasma and urine CTX-1 levels were not different between groups throughout the study. However, interindividual variations were greater in group 1 than in group 2. A significant decrease in CTX-1 levels was observed in plasma after the first administration in group 1, but not in urine; while in group 2, a significant decrease in CTX-1 concentrations was observed after treatment in both plasma and urine.

In conclusion, both dosage regimens of tiludronate produced similar plasma exposure and pharmacological effects in adult healthy horses.

(Paper received 19 July 2007; accepted for publication 12 December 2007)

C. Delguste, ULG - FMV - Clinique équine, Bât B41, Bd de Colonster n 20, B-4000 Sart-Tilman, Liege 1, Belgium. E-mail: cdelguste@ulg.ac.be

\section{INTRODUCTION}

Tiludronate, a non-nitrogen-containing bisphosphonate, inhibits osteoclast-mediated bone resorption by interfering with intracellular pathways required for normal cell function and survival (Rogers et al., 1999). In particular, it has been shown that tiludronate is metabolically incorporated into cytotoxic, nonhydrolysable analogues of ATP, accumulating intracellularly and leading to osteoclast apoptosis (Rogers et al., 1999; Rogers, 2003). It has also been shown to disrupt the cytoskeleton (Murakami et al., 1997) and to inhibit the activity of the proton pump (David et al., 1996) of resorbing osteoclasts. Bisphosphonates are widely used in human medicine in the treatment of different bone pathologies. Tiludronate is particularly indicated in the treatment of Paget's disease (Peris et al., 2002, 2006; Alexandersen et al., 2005), while more potent nitrogen-containing bisphosphonates, such as alendronate, zoledronate or ibandronate, are preferred in the treatment of postmenopausal osteoporosis, bone metastases and the hypercalcemia of malignancy (Bobba et al., 2006; Guay, 2006).

In horses, tiludronate presents a strong affinity for calcified tissues including bone, leading to a rapid distribution from plasma and an accumulation into deep compartments. It is not metabolized and is excreted by glomerular filtration (CEVA Santé Animale, unpublished data). These are pharmacokinetic (PK) characteristics shared by all bisphosphonates in other species including humans (Fleisch, 1997; Davi et al., 1999; Cremers et al., 2005; Lasseter et al., 2005). Bisphosphonates can persist in bone for several years after administration by forming complexes with hydroxyapatite crystals, until being finally absorbed by active osteoclasts where they exert their inhibitory action (Lasseter et al., 2005). In humans, the half-lives of the bisphosphonates are reported to be around a few days with values ranging from $2 \mathrm{~h}$ to 11 days depending on molecule, 
method and study design (Barrett et al., 2004; Lasseter et al., 2005; Yun et al., 2006), while bone half-lives are reported to be around 11 years (Lasseter et al., 2005).

The pharmacodynamic (PD) effects of bisphosphonates in humans have most commonly been estimated using the osteoporotic fracture risk reduction, the bone mineral density (BMD) assessment at different zones of interest (Reid, 2006) and by the measurement of biomarkers of bone metabolism in plasma or urine (Ravn et al., 2002; Cremers et al., 2005; Reginster et al., 2005). In horses, several blood biomarkers of bone metabolism have been tested successfully, including the carboxy-terminal cross-linking telopeptide of type I collagen (CTX-1) as a marker of bone resorption (Kellerhouse et al., 2000; Delguste et al., 2007). In human medicine, CTX-1 is commonly assessed in both plasma and urine, as it is considered as one of the most relevant markers in the monitoring of a bisphosphonate treatment (Reginster et al., 2005; Peris et al., 2006).

Tiludronate is licensed in Europe for the treatment of degenerative joint disease of the tarsus (bone spavin) and navicular disease in horses, at a dosage of $0.1 \mathrm{mg} / \mathrm{kg}$ body weight (b.w.) by intravenous (i.v.) bolus once daily for 10 consecutive days. Efficacy of this dosage has been confirmed by a clinical study in horses suffering from navicular disease (Denoix et al., 2003). Previous studies have evaluated the safety (Varela et al., 2002) and efficacy (Coudry et al., 2007; Delguste et al., 2007) of a single dose of $1 \mathrm{mg} / \mathrm{kg}$ b.w. by slow i.v. infusion. As the latter protocol may be considered a more practical dosage regimen by some, this study was performed to compare the PK and PD of these two dosage regimens in healthy adult horses.

\section{MATERIAL AND METHODS}

\section{Study design}

A unicentric parallel design study was conducted using two groups of six horses. Twelve healthy 3- to 5-year-old Standardbred horses were selected for this study, among which six were mares and six were geldings.

To be included in the study, horses had to: (1) be normal on physical examination, (2) have a lameness score $\leq 2$ on a scale of 5 (Stashak, 1998), (3) have values of serum urea and creatinine concentrations within the reference range (as an indirect assessment of kidney function) and (4) have no history of previous treatment with tiludronate or corticosteroids.

For the lameness examination, horses were observed while walking in a straight line and in small circles in both directions, then while trotting in a straight line. If the gait was considered abnormal, flexion tests followed by movement were performed on the suspected limb in order to confirm the suspicion of lameness. If lameness was observed in several limbs, the lameness score was based on the most severely affected limb.

Blood samples for measuring serum urea and creatinine concentrations were obtained by venipuncture of the right jugular vein. Blood sample was collected in sterile $5 \mathrm{~mL}$
Vacutainer glass tubes with no additives, and immediately submitted for analysis by colorimetry.

The horses were randomly assigned to a treatment group according to gender, so that each group consisted of three mares and three geldings. Horses of group 1 (aged $3.5 \pm 0.8$ years, weighing $441 \pm 28 \mathrm{~kg}$, mean $\pm \mathrm{SD}$ ) were administered tiludronate as an i.v. bolus of $0.1 \mathrm{mg} / \mathrm{kg} \mathrm{b.w}$. once daily for 10 consecutive days. Horses of group 2 (aged $3.0 \pm 0.0$ years, weighing $471 \pm 66 \mathrm{~kg}$ ) were administered tiludronate as a single constant rate infusion (CRI) at a total dose of $1 \mathrm{mg} / \mathrm{kg}$ b.w.

To reduce the possible influence of estrus cycle on the concentrations of CTX-1 in blood and urine, all mares underwent ultrasonographic examination of the reproductive tract 710 days before treatment administration. Mares found to be in diestrus were administered an injection of cloprostenol (Estrumate ${ }^{\circledR}$; Schering Plough, Kenilworth, NJ, USA) to induce luteolysis such that all mares were in the same phase of the estrus cycle at the time of treatment administration.

\section{Tiludronate administration}

Two products were tested: the commercial formulation of tiludronate (Tildren ${ }^{\circledR}$; CEVA Santé Animale, Libourne, France) (10 vials each containing $50 \mathrm{mg}$ tiludronate) and a nonmarketed formulation containing $500 \mathrm{mg}$ tiludronate per vial. Both products were presented as lyophilized powder extemporaneously reconstituted with saline (Baxter, Lessines, Belgium) as a $0.5 \%$ (group 1) or 2\% (group 2) injectable solution of tiludronate. The volume of reconstituted solution to be administered to each horse was calculated on the basis of b.w., and rounded to the nearest $0.5 \mathrm{~mL}$. Horses of group 1 received 10 daily bolus i.v. administrations of $0.1 \mathrm{mg} / \mathrm{kg}$ b.w. (0.0991 \pm $0.0018 \mathrm{mg} / \mathrm{kg} \mathrm{b.w}$.) of tiludronate from day 0 to day 9 in the left jugular vein. Horses of group 2 received a single CRI of a total dose of $1 \mathrm{mg} / \mathrm{kg}$ b.w. $(0.998 \pm 0.006 \mathrm{mg} / \mathrm{kg}$ b.w.) at an estimated rate of $25 \mathrm{~mL} / \mathrm{min}$ of tiludronate on day 0 as a $1-\mathrm{L}$ i.v. infusion in the left jugular vein. To obtain one litre of final solution for each horse in group 2, independently of the horse's b.w., a volume of saline (Baxter) equivalent to the volume of reconstituted $2 \%$ solution necessary to treat the horse was removed from a 1L bag (Baxter) before adding the reconstituted solution. All treatments were administered between $8 \mathrm{Am}$ and 12 PM. Any abnormal behaviour of the horses during or immediately after the administration of treatments was recorded.

\section{Tiludronate assay}

Blood samples for tiludronate assay were collected from the right jugular vein, into sterile Vacutainer glass tubes with heparin following the schedule presented in Table 1.

Plasma was separated by centrifugation $(1500 \mathrm{~g}$ at room temperature for $15 \mathrm{~min}$ ) and stored at $-20{ }^{\circ} \mathrm{C}$ within $1 \mathrm{~h}$ of collection until analysis.

Urine collection for tiludronate assay was performed using plastic bags tied to specially designed gender-specific harnesses 
Table 1. Plasma and urine sampling schedule for the tiludronate assay in 12 Standardbred horses

Group $1(n=6)$ : 10 daily administrations of $0.1 \mathrm{mg} / \mathrm{kg}$ b.w. tiludronate as i.v. bolus
Group $2(n=6)$ : single administration of $1 \mathrm{mg} / \mathrm{kg}$ b.w. tiludronate as slow infusion

\begin{tabular}{|c|c|c|}
\hline \multirow[t]{2}{*}{ Pretreatment } & Plasma: just before bolus 1 & Plasma: just before start of infusion \\
\hline & Urine: single sample on day -1 & Urine: single sample on day -1 \\
\hline & $\begin{array}{l}5,10,15,30 \text { min and } 1,2,4,8,12 \text { and } 24 \mathrm{~h}^{*} \text { after bolus } 1 \\
8 \text { and } 24 \mathrm{~h}^{*} \text { after bolus } 2-9\end{array}$ & $\begin{array}{l}5,10,15 \text { and } 30 \text { min after start of infusion } \\
\text { End of infusion (time recorded) }\end{array}$ \\
\hline & $\begin{array}{l}\text { Urine: continuous collection starting immediately after } \\
\text { bolus } 1\end{array}$ & Urine: continuous collection starting with infusion \\
\hline \multirow[t]{4}{*}{ Post-treatment } & Plasma: & Plasma: \\
\hline & Urine: & Urine: \\
\hline & Continuous collection until $168 \mathrm{~h}$ after bolus 10 & Continuous collection until $168 \mathrm{~h}$ after start of infusion \\
\hline & $\begin{array}{l}\text { Over } 24 \text {-h periods, respectively, } 10,20,30,40,50 \text { and } \\
60 \text { days after bolus } 10 \text { (i.e. on days 19, 29, 39, 49, } 59 \text { and } \\
69 \text { ) }\end{array}$ & $\begin{array}{l}\text { Over } 24 \text {-h periods, respectively, } 10,20,30,40,50 \text { and } \\
60 \text { days after infusion (i.e. on days } 10,20,30,40,50 \\
\text { and } 60 \text { ) }\end{array}$ \\
\hline
\end{tabular}

*Blood samples taken at $24 \mathrm{~h}$ after bolus injections 1-9 were taken immediately before the next bolus administration.

(HFL, Newmarket, England), following the schedule presented in Table 1.

After each micturition, the time and horse number were recorded, and bags were removed for sampling while empty bags were tied to the harness. Two sets of individual bags were labelled with the horse's number to avoid cross-contamination, and were alternately used until damaged in order to 'wash' the deposits of the previous micturitions, and so to minimize the possible losses because of these deposits.

For sampling, urine bags were gently shaken to avoid large deposits on the bottom before being poured into a graded, 2-L cylinder for careful volume measurement of the total micturition (rounded to the nearest $20 \mathrm{~mL}$ ). Urine was then magnetically mixed using a magnetic stirring rod while a representative sample equivalent to $1 / 100$ of the total volume of the micturition was sampled and stored at $4{ }^{\circ} \mathrm{C}$ within $1 \mathrm{~h}$ of collection until pooling. Urine samples were pooled by $4-\mathrm{h}$ periods on day 0 , and by 24 -h periods on subsequent days. To represent better the accumulation of drug in urine during a given period, samples obtained from a micturition occurring within the first $30 \mathrm{~min}$ of a collection period were pooled with the samples from the previous period. The actual volume of the pool was evaluated carefully in a 50- or 250-mL cylinder, rounded to the nearest $0.5 \mathrm{~mL}$ and recorded for comparison with the calculated expected volume. Urine was then homogenized again by magnetic shaking during collection of the final samples, which were stored at $-20{ }^{\circ} \mathrm{C}$ within $28 \mathrm{~h}$ of collection of the first sample of the pool until analysis.

Both plasma and urinary concentrations of tiludronate were measured by high performance liquid chromatography (HPLC) with UV detection. The method was validated in terms of precision, accuracy and recovery. The limit of quantification (LOQ) was 0.025 and $0.05 \mathrm{mg} / \mathrm{L}$, and the limit of detection was 0.011 and $0.0 \mathrm{mg} / \mathrm{L}$, in plasma and urine respectively. Intraday coefficients of variation ranged from $-0.8 \%$ to $6.9 \%$ and from $-3.2 \%$ to $5.19 \%$ in plasma and urine, respectively. Interday coefficients of variation ranged from $1.87 \%$ to $5.36 \%$ and from $-3.6 \%$ to $4.88 \%$ in plasma and urine, respectively. Plasma concentrations vs. time curves were plotted for PK analysis. The urine concentrations were multiplied by the total volume of urine collected during the collection period corresponding to the pool in order to obtain the total amount of tiludronate excreted by collection period. These amounts were then added to obtain the total amount of tiludronate excreted by each horse and a cumulative urine excretion vs. time curve was plotted, for comparison between treatment groups.

\section{CTX-1 assay}

Blood and urine samples for CTX-1 assay were collected before treatment on days $-5,-3$, and -1 in both groups; during treatment on days 1 and 5 in group 1 only; and 1, 3, 6, 10, 20, 30 and 60 days after treatment completion in both groups (i.e. on days $10,12,15,19,29,39$ and 69 in group 1 , and on days $1,3,6,10,20,30$ and 60 in group 2). After an overnight fast, blood samples were collected between $8.00 \mathrm{Am}$ and 10.00 AM by venipuncture of the right jugular vein into sterile Vacutainer glass tubes with ethylene diamine tetraacetic acid (EDTA), and urine samples were collected from the micturition the closest to 10.00 AM. In blood and urine, respectively plasma and supernatant were separated by centrifugation $(1500 \mathrm{~g}$ at room temperature) and stored at $-20{ }^{\circ} \mathrm{C}$ within $1 \mathrm{~h}$ after collection until analysis. Quantification of CTX-1 concentration was performed in both plasma and urine by an automated immunoenzymatic assay previously validated in horses (Crosslaps Elecsys; Roche Diagnostics, Basel, Switzerland) (Carstanjen et al., 2004).

\section{PK analysis}

Pharmacokinetic analyses were performed using KinETicA version 4.4.1 software (Thermo electron, Mountain View, CA, USA). 
For both groups, a noncompartmental approach was used to estimate PK parameters.

Assuming that clearance $(\mathrm{Cl})$ remained unchanged between the two dosing regimens, and that steady-state was achieved by day 10 for group 1 , relative plasma bioavailability $\left(F_{\mathrm{p}}\right)$ was assessed using group 1 (currently approved dosage rate) as reference. Hence, the total plasma exposure between zero to infinity for group 2, represented by the total area under the curve $\left(A U C_{\text {tot }}\right)$, was compared with the area under the curve at steady-state $\left(A U C_{\mathrm{ss}}\right)$ corresponding to the total plasma exposure from 0 to $24 \mathrm{~h}$ measured at the last dose for group 1, multiplied by the dose ratio (Rowland \& Tozer, 1995).

Urinary tiludronate excretion parameters were also to be used to determine relative bioavailability. These were to be obtained from a cumulative urine excretion vs. time curve. Relative urine bioavailability $\left(F_{\mathrm{u}}\right)$ is determined by the ratio of total amount of drug excreted in urine to last sampling $\left(\mathrm{Xu}_{\text {tot }}\right)$ (Rowland \& Tozer, 1995).

\section{PD analysis}

The PD effects of tiludronate were assessed by measurement of plasma and urine CTX-1 concentrations. The results were expressed as percentages of baseline value for each horse. Baseline values were calculated as the median of the three values from days -5 to -1 .

\section{Statistical analysis}

Statistical analysis was run on sAs software, version 8.2 (SAS Institute Inc., Cary, NC, USA).

After normalization of the data, a linear mixed model was used to describe the experiment, as follows:

$$
Y_{g i j k}=\grave{\imath}+G_{i}+S_{j}+(G S)_{i j}+D(G S)_{i j k}+a_{i j l}+e_{i j k l}
$$

where $Y$ is the CTX-1 measurement, $i$ is the grand mean, $G_{i}, S_{j}$ and $D_{k}$ are the main effects of group, gender and date respectively, and $(G S)_{i j}$ are the group-gender interaction effects. Lower case letters represent group number $(i)$, gender $(j)$, date of measurement $(k)$ and animal number $(l)$. The $a_{i j l}$ represent the random effects of animals while $e_{i j k l}$ are the random errors associated with the measurements. Standard stochastic assumptions are made that the random effects $a_{i j l}$ and $e_{i j k l}$ are normally distributed with zero means and variances $\sigma_{\mathrm{a}}{ }^{2}$ and $\sigma_{e}{ }^{2}$ respectively. The $a_{i j l}$ were assumed to be independent but fluctuations were detected in the variances over time so the covariance structure was modelled with a first-order autoregressive structure (Proc MixеD, Type $=\mathrm{AR}(1)$; SAS Institute Inc., 1999) for which the co-variances between repeated measures on the same animal decrease exponentially with time. Finally, least-squares means were obtained for the main and interaction effects along with all pair-wise comparisons.

For the other variables $\left(A U C, C l\right.$ and $\left.\mathrm{Xu}_{\text {tot }}\right)$, the model included only the fixed effects $G_{i}, S_{j}$ and $(G S)_{i j \text {; }}$ the residuals were assumed independent and identically normally distributed with zero mean and common variance.
The significance threshold was set at 5\% ( $P$-value <0.05).

The protocol was approved by the Animal Care Committee of the University of Liege, which abides by the requirements of the directive 86/609 of the European Community Council. Experiments followed guidelines equivalent to those in 'Guide to the care and use of experimental animals' published by the Laboratory Animal Resources Commission on Life Sciences National Research Council (National Academy press, Washington, DC, 1996).

The study also complied with the International Cooperation and Harmonization of Technical Requirements for Registration of Veterinary Medicinal Products entitled Guideline 9 Good Clinical Practice for the animal phase. The analytical phases for tiludronate and CTX-1 determinations were performed in accordance with the Directive 2004/10/EC of the European Parliament and the Council of 11 February 2004 and 'Arrêté du 28 Janvier 2005 relatif aux Bonnes Pratiques de Laboratoire pour les médicaments vétérinaires: JO du 20/02/2005'.

\section{RESULTS}

Horse 11 (group 2) showed slight signs of restlessness (kicking) during the infusion, which could possibly be because of abdominal discomfort. No further clinical signs were observed after the end of infusion in this horse. None of the other horses showed adverse effects during or after treatment in either group.

The rate of infusion in group 2 was $25.77 \pm 2.86 \mu \mathrm{g} / \mathrm{kg} / \mathrm{min}$. Individual mean daily outputs of urine ranged from 5.32 to $12.34 \mathrm{~L} /$ day $(10.98-27.07 \mathrm{~mL} / \mathrm{kg} /$ day) with a median value of $6.95 \mathrm{~L} /$ day $(16.16 \mathrm{~mL} / \mathrm{kg} /$ day). Urine daily output was similar in group 1 (range 5.32-12.34, median 6.26 L/day) and group 2 (range 5.69-10.51, median $7.71 \mathrm{~L} /$ day).

\section{PK analysis}

Plasma concentrations of tiludronate vs. time curves (mean $\pm \mathrm{SD}$ ) for groups 1 and 2 are shown in Figs $1 \& 2$, respectively.

The main PK parameters of interest derived from the noncompartmental analysis are given in Tables 2 and 3. After determining that the extrapolated portion of the AUC represented no more than $10 \%$ of the total estimated $A U C$, it was determined that the $A U C_{\text {tot }}$ could be used for group 2 .

There was no significant difference $(P=0.743)$ between the $A U C$ corrected for dosage for group $1\left(A U C_{\mathrm{ss}}\right)$ and group 2 $\left(A U C_{\text {tot }}\right)$. There was no significant difference between groups for $\mathrm{Cl}(P=0.564)$. There were no significant differences between males and females for $A U C(P=0.509)$ and $C l(P=0.583)$.

As $\mathrm{Cl}$ was not statistically different between groups, the aforementioned formula could be adequately used to calculate $F_{\mathrm{p}}$, using the mean $A U C$ for each group only. This was $103.1 \%$.

Several horses in both groups had tiludronate urine concentrations below LOQ at different postadministration time intervals, especially in group 1 (data not shown). Tiludronate concentra- 

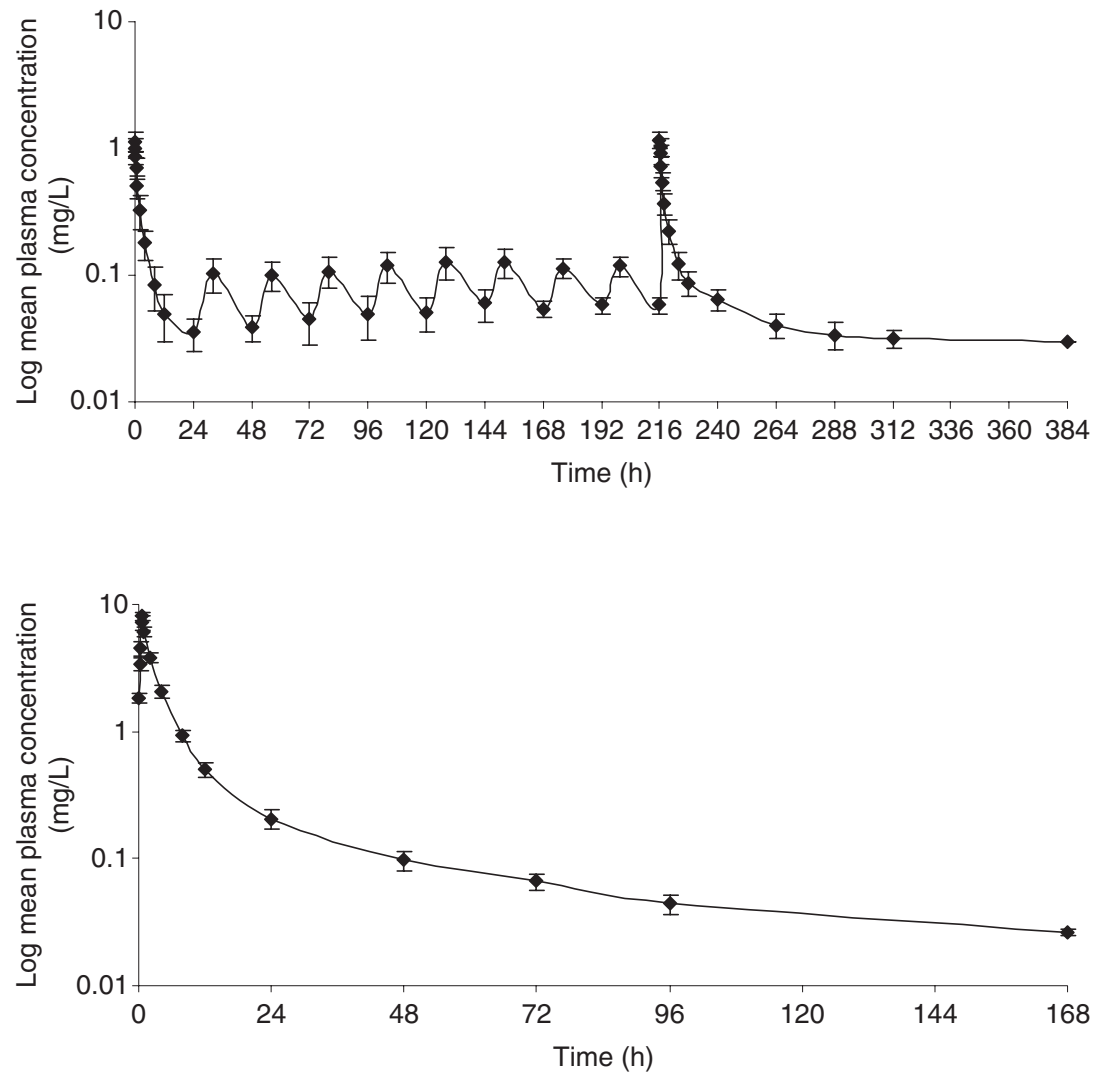

Fig. 1. Mean $( \pm S D) \log$ plasma tiludronate concentration vs. time in Standardbred horses after daily intravenous administration as bolus of $0.1 \mathrm{mg}$ tiludronate $\mathrm{kg}$ once daily for 10 consecutive days (group $1, n=6$ ).

Table 2. Steady-state pharmacokinetic parameters of tiludronate in plasma following daily intravenous injections (as bolus) of $0.1 \mathrm{mg} / \mathrm{kg}$ b.w. of tiludronate for 10 consecutive days to six Standardbred horses (group 1)

\begin{tabular}{lcccccc}
\hline Horse & $A U C_{\mathrm{ss}}(\mathrm{mg} \cdot \mathrm{h} / \mathrm{L})$ & $A U M C_{\mathrm{ss}}(\mathrm{mg} \cdot \mathrm{h} / \mathrm{L})$ & $C_{\mathrm{ss}}(\mathrm{L} / \mathrm{h} / \mathrm{kg})$ & $C_{\text {min,ss }}(\mathrm{mg} / \mathrm{L})$ & $C_{\text {max,ss }}(\mathrm{mg} / \mathrm{L})$ & $C_{\text {ave }}(\mathrm{mg} / \mathrm{L})$ \\
\hline 1 & 3.62 & 23.54 & 0.027 & 0.047 & 1.198 & 0.151 \\
2 & 4.02 & 31.56 & 0.025 & 0.065 & 1.03 & 0.168 \\
3 & 3.62 & 27.17 & 0.027 & 0.058 & 0.955 & 0.151 \\
4 & 3.25 & 21.87 & 0.030 & 0.053 & 1.154 & 0.135 \\
5 & 3.05 & 20.06 & 0.032 & 0.052 & 1.204 & 0.127 \\
6 & 5.01 & 34.47 & 0.020 & 0.07 & 1.5 & 0.209 \\
$N$ & 6 & 6 & 6 & 6 & 6 & 1.46 \\
Mean & 3.76 & 26.44 & 0.027 & 0.058 & 1.174 & 0 \\
SD & 0.698 & 5.679 & 0.0042 & 0.0086 & 0.1881 & 0.157 \\
\hline
\end{tabular}

$C_{\text {ave }}$, average concentration.

Table 3. Pharmacokinetic parameters of tiludronate in plasma following one intravenous injection (as CRI) of a total dose of $1 \mathrm{mg} / \mathrm{kg}$ b.w. of tiludronate to six Standardbred horses (group 2)

\begin{tabular}{lcccccc}
\hline Horse & $A U C_{\text {tot }}(\mathrm{mg} \cdot \mathrm{h} / \mathrm{L})$ & $K_{\mathrm{e}}\left(\mathrm{h}^{-1}\right)$ & Elimination half-life $(\mathrm{h})$ & $M R T(\mathrm{~h})$ & Clearance $(\mathrm{L} / \mathrm{h} / \mathrm{kg})$ & $V_{\mathrm{d}}(\mathrm{L} / \mathrm{kg})$ \\
\hline 7 & 38.15 & 0.018 & 37.57 & 18.17 & 0.026 \\
8 & 37.56 & 0.011 & 65.24 & 37.48 & 0.027 \\
9 & 40.66 & 0.012 & 58.05 & 33.77 & 0.025 & 0.029 \\
10 & 34.72 & 0.015 & 47.17 & 25.89 & 0.026 \\
11 & 37.77 & 0.016 & 42.82 & 22.84 & 0.022 \\
12 & 45.56 & 0.012 & 57.62 & 62.931 & 6 \\
$N$ & 6 & 6 & 51.41 & 28.51 & 0.07 & 1.94 \\
Mean & 39.07 & 0.014 & 10.56 & 7.40 & 0.026 \\
SD & 3.70 & 0.003 & & & 0.0022 \\
\hline
\end{tabular}


tions were also below LOQ in all subjects in both groups by 20 days after the last administration. The total amount of tiludronate excreted in urine was significantly lower in group 1 than in group $2(P=0.0003)$, but no significant gender effect was observed for this parameter $(P=0.110)$. Because of the large number of missing data (concentrations below LOQ) for several time-points in both groups of horses, PK analyses could not be performed on urine tiludronate excretion data, and the relative bioavailability could not be determined.

\section{PD analysis}

Plasma CTX-1 concentrations (expressed as percentage of baseline value) vs. time curves of groups 1 and 2 are shown in Figs 3 \& 4, respectively. Baseline is the median of the three pretreatment values, and is by definition 100\%. Horse 6 (mare from group 1) had multiple inexplicable plasma concentrations, and was excluded from the analysis for CTX-1 in both plasma and urine.

In plasma, a significant decline in plasma CTX-1 concentrations was seen between day 0 and day 1 in both groups ( $P=0.047$ and 0.005 in groups 1 and 2 , respectively). This difference was still significant on day 3 in group $2(P=0.036)$. There were no significant differences in the evolution of plasma $(P=0.488)$ or urine $(P=0.827)$ CTX-1 concentrations between groups.

A significant transient decrease in urinary CTX-1 was seen between day 0 and day 1 in group $2(P=0.028)$, but not in group $1(P=0.219)$ (data not shown).
No gender effect was seen on CTX-1, in plasma $(P=0.973)$ or in urine $(P=0.525)$.

\section{DISCUSSION}

This study established that plasma exposure to tiludronate was similar after administered by two different dosage regimens with a same cumulative dose of $1 \mathrm{mg} / \mathrm{kg}$. Moreover, no differences between groups were evidenced in the overall evolution of the bone resorption marker CTX-1. This suggests that the administration of 10 daily boluses could be practically replaced by a single CRI.

The bioequivalence is based on the assumption that a similar plasma exposure to a drug gives rise to a similar effect (Toutain \& Koritz, 1997). Hence, bioequivalence implies similar bioavailabilities of two drug formulations. Nevertheless, plasma concentration profiles have to be compared after administration of the two products by the same route and at the same dose. For comparison of the same product given by the same route at the same total dose, but administered as single or divided doses, the guidelines have to be adapted. In this study, standard parameters for the assessment of bioequivalence, such as maximal plasma concentration and time for maximal plasma concentration were not considered relevant for the comparison of the same cumulative dose of the drug given as a CRI or as 10 daily bolus injections. Therefore, this study focused on comparing plasma exposure to the drug (i.e. determination of relative bioavailability). The very long tissue half-life of tiludronate
Fig. 3. Median and range of plasma CTX-1 concentrations (expressed as percentage of baseline value) vs. time in Standardbred horses after daily intravenous administration of tiludronate as boluses of $0.1 \mathrm{mg} / \mathrm{kg}$ once daily for 10 consecutive days (group $1, n=5$ ).

Fig. 4. Median and range of plasma CTX-1 concentrations (expressed as percentage of baseline value) vs. time in Standardbred horses after a single CRI of tiludronate of $25.77 \pm 2.86 \mu \mathrm{g} / \mathrm{kg} / \mathrm{min}$ and a total dose of $1 \mathrm{mg} / \mathrm{kg}$ (group $2, n=6$ ).
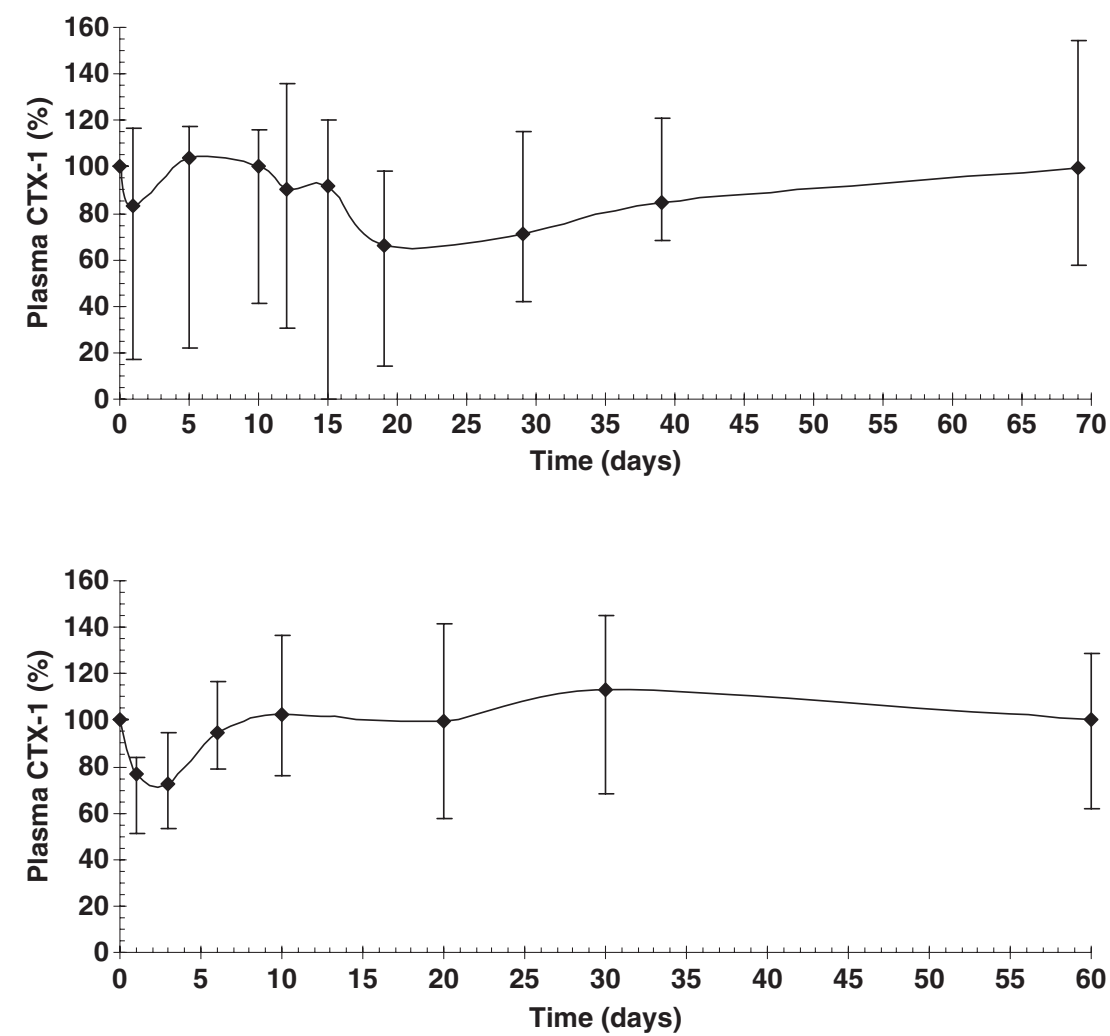
prohibited the use of a cross-over designed study. Constancy of $\mathrm{Cl}$ is the only requirement for relative bioavailability calculation (Rowland \& Tozer, 1995). As tiludronate exerts its inhibitory action after endocytosis by active osteoclasts from bone undergoing resorption (Rogers et al., 1999), it is likely that bone concentrations of tiludronate would be a better predictor of clinical effect than plasma concentrations (Cremers et al., 2005). However, invasive methods are required to assess bone concentrations. Moreover, bone concentrations are not homogeneous between and within bones (Davi et al., 1999). Therefore, pharmacological effects of bisphosphonates are thought to be site-dependent as they depend on both local drug concentration and local resorption activity for drug endocytosis (Sato et al., 1991). The total amount of tiludronate stored in bones could nevertheless reflect the total effect. As tiludronate is not metabolized and excreted almost exclusively in urine (CEVA, unpublished data), it was suggested that calculation of plasma exposure along with cumulative urine excretion would permit to assess the total amount of tiludronate stored in bones. The comparison of relative bioavailability from both plasma and urine could have permitted indirect comparison of bone exposure between dosage regimens. In turn, bone exposure could be related to CTX-1. Unfortunately, the lack of sensitivity of the tiludronate assay did not allow accurate measurement of tiludronate concentrations in urine. The comparison of PK between groups was therefore limited to plasma exposures. These were compared after confirming that $\mathrm{Cl}$ was dose-independent.

In the bolus group (group 1), it was assumed that steady-state had been reached by the 10th dose. This assumption was supported by the visual inspection of the mean concentration vs. time plots at 8 and $24 \mathrm{~h}$ after each administration, which showed a plateau from the 7 th administration. Moreover, the accumulation factor was limited $(1.36 \pm 0.124$, range 1.19 1.48), suggesting that the dosage interval (i.e. $24 \mathrm{~h}$ ) was inferior to but relatively close to the plasma half-life of tiludronate. This, in turn, suggested that a 10-day course of daily administrations was sufficient to consider that steady-state had been reached, as $90 \%$ of the plateau is reached after 3.3 half-lives and $99 \%$ after seven half-lives in multi-doses regimens. Relative plasma bioavailability was therefore determined using $A U C_{\text {tot }}$ for the infusion group (group 2) and $A U C_{\mathrm{ss}}$ for the bolus group, multiplied by the dose ratio. A result close to $100 \%$ was expected to confirm that the two dosage regimens produced a comparable plasma exposure, as stated by the statistical analysis. With a result of $103 \%$, a very slight advantage regarding plasma exposure in favour to the infusion group was observed.

It is worth pointing out that the missing urine data were not because of urine wasting during collection phases. Urine losses caused by technical reasons were insignificant relative to the total volume. Moreover, the urine daily output was within normal limits (5-15 L/day) (Tasker, 1966) for all horses of the study. Therefore, the main limiting factor was the sensitivity of the assay, particularly for group 1, where lower urine concentrations were measured. Another potential limitation in the assessment of urinary tiludronate was the homogenization of urine. Indeed, equine urine contains large amounts of calcium crystals which may have adsorbed tiludronate. Particular attention was paid to homogenization of the sediment during urine sampling, but losses could have occurred. Whatever the cause, the large number of missing data made urine excretion values irrelevant, particularly in group 1. Despite this, the visual inspection of the curves of cumulative urinary excretion suggests that the arbitrary choice of continuous collection until 7 days postlast administration was adequate to reach the plateau in all horses. In both groups, most of the tiludronate had been excreted by $24 \mathrm{~h}$ after the last administration $(92.3 \%$ and $89.0 \%$ of the total amount to be excreted in group 1 and 2, respectively), and tiludronate was no longer quantifiable by 20 days post-treatment in either group. Nevertheless, with a higher sensitivity of the tiludronate assay in urine, the actual plateau of cumulative excretion could have been reached later than it appeared in this study. This would be consistent with the long residence time of tiludronate in bone. This would also imply that the actual terminal half-life in plasma could be longer than it appeared from the plasma vs. time curves in the present study, and that a longer sampling time along with a lower LOQ for the HPLC method used for both plasma and urine would have been required.

To assess further the bioequivalence of the two dosage regimens of tiludronate in horses, an evaluation of their respective pharmacological effects was attempted. It was already known that there was no difference in adverse effects between these two dosage regimens (Varela et al., 2002). However, this is the first time that the antiresorptive effects of the two dosages had been examined. Objective assessment of the effects of tiludronate in horses is challenging. For this purpose, different techniques of bone imaging and density measurement have been tested (Delguste et al., 2007). In human clinical trials, BMD and biochemical markers of bone turnover are commonly used as surrogate markers of the efficacy of bisphosphonates (i.e. reduction of fracture risk) (Reid, 2006), although they have not yet been validated for the management of individual osteoporotic patients. In equine medicine, BMD can be measured only in the cannon bone, which is generally not the target bone of a tiludronate treatment. Blood CTX-1 is thought to be a reliable marker of bone resorption in the equine species, and as such is thought to be reflective of the general bone resorption status of an individual (Kellerhouse et al., 2000; Billinghurst et al., 2003; Camacho \& Kleerekoper, 2006). As in humans, large interindividual variations are observed in basal CTX-1 concentrations in horses; hence its evolution is commonly expressed in percentage of baseline value (Kellerhouse et al., 2000; Billinghurst et al., 2003; Delguste et al., 2007). Variations can arise not only because of age, gender, breed or disease, among others, but also because of circadian, hormonal or alimentary reasons (Hannon \& Eastell, 2000; Lepage et al., 2001). Therefore, standardization of both horses' characteristics and sampling procedures are of paramount importance in the design of a study evaluating biochemical markers of bone turnover. Furthermore, in this study, lameness was evaluated before inclusion in an attempt to exclude horses suffering from significant bone pathologies susceptible to affect baseline value of 
CTX-1 significantly. Grade-1 lameness was considered as unlikely to reflect significant bone disease, and was not an exclusion criterion. Retrospectively, the two grade-1 lame horses, which failed to present suggestive clues about the origin of the lameness (horses 5 and 10), were the two horses with the highest plasma CTX-1 baseline value of their respective group, while the other three grade-1 lame horses of the study (horses 2, 3 and 11) had rather low baseline values. The subsequent evolution of the plasma CTX-1 levels of horses 5 and 10 expressed as percentages of baseline value was similar to that of the rest of their respective groups, although their levels remained in the lowest range in the long term (from 30 and 10 days posttreatment for horses 5 and 10, respectively). Therefore, it cannot be ruled out that some degree of bone pathology had an impact on CTX-1 results, and that the tiludronate treatment could have inhibited an underlying process of enhanced bone resorption during the whole study in these horses.

The sensitivity of blood CTX-1 makes it useful in the monitoring of a tiludronate treatment in horses (Delguste et al., 2007). In human medicine, serum and/or urine CTX-1 are PD end-points commonly used in the efficacy evaluation of a bisphosphonate treatment (Tanko et al., 2003; Nenonen et al., 2005; Reginster et al., 2005; Cremers \& Garnero, 2006; Ilter et al., 2006; Peris et al., 2006; Lein et al., 2007). Correlations have been found between the serum CTX-1 response to a bisphosphonate therapy and reduction of fracture risk (Cremers \& Garnero, 2006). The overall evolution of CTX-1 observed in this study showed no difference between groups, and in plasma, a decrease in CTX-1 concentrations was observed in both groups $24 \mathrm{~h}$ after the first administration of tiludronate. While this decrease was maximal 3 days after the infusion, the lowest trough of the curve was reached 10 days after completion of treatment in the bolus group. Nevertheless, no plasma CTX-1 assessment was performed between day 1 and day 5 in this group, and a transient trough similar to the one observed in group 2 on day 3 cannot be ruled out. Although at different time-points, the maximal median inhibition of bone resorption was similar in both groups, at around $70 \%$ of the baseline value. For undetermined reasons, this CTX-1 decrease was less than that in a previous study, where serum CTX-1 declined by $50 \%$ after a $1 \mathrm{mg} / \mathrm{kg}$ tiludronate infusion (Delguste et al., 2007). In this study, the interindividual variations were very large in the bolus group in both plasma and urine, while evolution of CTX-1 seemed to present less variability in the infusion group. It was therefore suspected that tiludronate administered in 10 lower daily doses could have a less predictable effect on CTX-1 than a single CRI of the total dose, or that some horses could be nonresponders at the lower, repeated dosage. From the results of CTX-1 in the infusion group, it seems that in horses, the sensitivity of this marker is higher in plasma than in urine. Moreover, urine collection can be challenging in horses, thus favoring the assessment of blood rather than urine CTX-1 in future studies. Therefore, urine CTX-1 results will not be further discussed.

In human medicine, studies comparing different dosage regimens of a same bisphosphonate have been reported (Tanko et al., 2003; Reid, 2006). Indeed, less-frequent dosing is of great interest as it can improve compliance with bisphosphonate treatments. Such dosage regimen adaptations are based on the concept that inhibition of bone resorption by a bisphosphonate is determined by the total dose administered within a given period (Tanko et al., 2003; Bauss \& Russell, 2004). However, under suboptimal dosing conditions, the overall efficacy of the antiresorptive treatment can also depend on the dynamics of loading the skeletal system, i.e., frequency of dosing (Tanko et al., 2003; Papapoulos \& Schimmer, 2007).

This study suggests that the administration of a single dose of $1 \mathrm{mg} / \mathrm{kg}$ b.w. tiludronate as a CRI and daily i.v. administrations as boluses of $0.1 \mathrm{mg} / \mathrm{kg}$ for 10 consecutive days, produce similar plasma exposure and pharmacological effects in horses. Nevertheless, the response of the bone resorption marker CTX-1 to the drug seemed to be less reproducible when the total dose of $1 \mathrm{mg} / \mathrm{kg}$ was administered as 10 daily doses than when it was given as a single dose. The current multiple dose regimens could be replaced by a single CRI in horses. Further clinical studies are warranted to investigate efficacy of tiludronate on large cohorts of horses suffering from bone diseases, and to confirm the interest of CTX-1 as a biomarker useful in monitoring bisphosphonate treatment in these horses.

\section{ACKNOWLEDGMENTS}

The authors thank Fabrice Juillet for his technical assistance in biomarker assessment, as well as Drs Stéphanie Dujardin, Bénédicte Machiels, Mélanie Momont, Marine Rosengarten and Natacha Wiest for their valuable assistance.

This study was graciously funded by CEVA Santé Animale, Libourne Cedex, France.

\section{REFERENCES}

Alexandersen, P., Peris, P., Guanabens, N., Byrjalsen, I., Alvarez, L., Solberg, H. \& Cloos, P.A. (2005) Non-isomerized C-telopeptide fragments are highly sensitive markers for monitoring disease activity and treatment efficacy in Paget's disease of bone. Journal of Bone and Mineral Research, 20, 588-595.

Barrett, J., Worth, E., Bauss, F. \& Epstein, S. (2004) Ibandronate: a clinical pharmacological and pharmacokinetic update. Journal of Clinical Pharmacology, 44, 951-965.

Bauss, F. \& Russell, R.G. (2004) Ibandronate in osteoporosis: preclinical data and rationale for intermittent dosing. Osteoporosis International, 15, 423-433.

Billinghurst, R.C., Brama, P.A., van Weeren, P.R., Knowlton, M.S. \& McIlwraith, C.W. (2003) Significant exercise-related changes in the serum levels of two biomarkers of collagen metabolism in young horses. Osteoarthritis and Cartilage, 11, 760-769.

Bobba, R.S., Beattie, K., Parkinson, B., Kumbhare, D. \& Adachi, J.D. (2006) Tolerability of different dosing regimens of bisphosphonates for the treatment of osteoporosis and malignant bone disease. Drug Safety, 29, 1133-1152.

Camacho, P. \& Kleerekoper, M. (2006) Biochemical markers of bone turnover. In Primer on the Metabolic Bone Diseases and Disorders of 
Mineral Metabolism, 6th edn. Ed Favus, M.J., pp. 127-133. American Society for Bone and Mineral Research, Washington, DC.

Carstanjen, B., Hoyle, N.R., Gabriel, A., Hars, O., Sandersen, C., Amory, H. \& Remy, B. (2004) Evaluation of plasma carboxy-terminal crosslinking telopeptide of type I collagen concentration in horses. American Journal of Veterinary Research, 65, 104-109.

Coudry, V., Thibaud, D., Riccio, B., Audigie, F., Didierlaurent, D. \& Denoix, J.M. (2007) Efficacy of tiludronate in the treatment of horses with signs of pain associated with osteoarthritic lesions of the thoracolumbar vertebral column. American Journal of Veterinary Research, $68,329-337$.

Cremers, S. \& Garnero, P. (2006) Biochemical markers of bone turnover in the clinical development of drugs for osteoporosis and metastatic bone disease: potential uses and pitfalls. Drugs, 66, 2031-2058.

Cremers, S.C., Pillai, G. \& Papapoulos, S.E. (2005) Pharmacokinetics/pharmacodynamics of bisphosphonates: use for optimisation of intermittent therapy for osteoporosis. Clinical Pharmacokinetics, 44, 551-570.

Davi, H., Tronquet, C., Caix, J., Simiand, J., Briot, C., Berger, Y. \& Thiercelin, J.F. (1999) Disposition of tiludronate (Skelid) in animals. Xenobiotica, 29, 1017-1031.

David, P., Nguyen, H., Barbier, A. \& Baron, R. (1996) The bisphosphonate tiludronate is a potent inhibitor of the osteoclast vacuolar $\mathrm{H}(+)$ ATPase. Journal of Bone and Mineral Research, 11, 1498-1507.

Delguste, C., Amory, H., Doucet, M., Piccot-Crezollet, C., Thibaud, D., Garnero, P., Detilleux, J. \& Lepage, O.M. (2007) Pharmacological effects of tiludronate in horses after long-term immobilization. Bone, 41, 414-421.

Denoix, J.M., Thibaud, D. \& Riccio, B. (2003) Tiludronate as a new therapeutic agent in the treatment of navicular disease: a double-blind placebo-controlled clinical trial. Equine Veterinary Journal, 35, 407413.

Fleisch, H.A. (1997) Bisphosphonates: preclinical aspects and use in osteoporosis. Annals of Medicine, 29, 55-62.

Guay, D.R. (2006) Ibandronate, an experimental intravenous bisphosphonate for osteoporosis, bone metastases, and hypercalcemia of malignancy. Pharmacotherapy, 26, 655-673.

Hannon, R. \& Eastell, R. (2000) Preanalytical variability of biochemical markers of bone turnover. Osteoporosis International, 11 (Suppl. 6), S30-S44.

Ilter, E., Karalok, H., Tufekci, E.C. \& Batur, O. (2006) Efficacy and acceptability of risedronate $5 \mathrm{mg}$ daily compared with $35 \mathrm{mg}$ once weekly for the treatment of postmenopausal osteoporosis. Climacteric, 9, 129-134.

Kellerhouse, P.L., Brown, C., Newhall, K., Judd, K. \& Thompson, D. (2000) Assessment of bone resorption marker assays in Thoroughbred horses. Journal of Bone and Mineral Research, 15, S526.

Lasseter, K.C., Porras, A.G., Denker, A., Santhanagopal, A. \& Daifotis, A. (2005) Pharmacokinetic considerations in determining the terminal elimination half-lives of bisphosphonates. Clinical Drug Investigation, 25, 107-114.

Lein, M., Wirth, M., Miller, K., Eickenberg, H.U., Weissbach, L., Schmidt, K., Haus, U., Stephan, C., Meissner, S., Loening, S.A. \& Jung, K. (2007) Serial markers of bone turnover in men with metastatic prostate cancer treated with zoledronic acid for detection of bone metastases progression. European Urology, 52, 1381-1387.

Lepage, O.M., Carstanjen, B. \& Uebelhart, D. (2001) Non-invasive assessment of equine bone: an update. Veterinary Journal, 161, 10-22.

Murakami, H., Takahashi, N., Tanaka, S., Nakamura, I., Udagawa, N., Nakajo, S., Nakaya, K., Abe, M., Yuda, Y., Konno, F., Barbier, A. \& Suda, T. (1997) Tiludronate inhibits protein tyrosine phosphatase activity in osteoclasts. Вопе, 20, 399-404.
Nenonen, A., Cheng, S., Ivaska, K.K., Alatalo, S.L., Lehtimaki, T., Schmidt-Gayk, H., Uusi-Rasi, K., Heinonen, A., Kannus, P., Sievanen, H., Vuori, I., Vaananen, H.K. \& Halleen, J.M. (2005) Serum TRACP 5b is a useful marker for monitoring alendronate treatment: comparison with other markers of bone turnover. Journal of Bone and Mineral Research, 20, 1804-1812.

Papapoulos, S.E. \& Schimmer, R.C. (2007) Changes in bone remodelling and antifracture efficacy of intermittent bisphosphonate therapy: implications from clinical studies with ibandronate. Annals of the Rheumatic Diseases, 66, 853-858.

Peris, P., Alvarez, L., Monegal, A., Guanabens, N., Duran, M., Echevarria, M., Ros, I., Ballesta, A.M. \& Munoz-Gomez, J. (2002) Effect of surgical menopause and Paget's disease of bone on the isomerization of type I collagen carboxyterminal telopeptide: evolution after antiresorptive therapy. Journal of Bone and Mineral Metabolism, 20, 116-120.

Peris, P., Alvarez, L., Vidal, S., Kasper, D., Leeming, D.J., Monegal, A., Angeles Martinez, M., Pons, F. \& Guanabens, N. (2006) Biochemical response to bisphosphonate therapy in pagetic patients with skull involvement. Calcified Tissue International, 79, 22-26.

Ravn, P., Neugebauer, G. \& Christiansen, C. (2002) Association between pharmacokinetics of oral ibandronate and clinical response in bone mass and bone turnover in women with postmenopausal osteoporosis. Bone, 30, 320-324.

Reginster, J.Y., Wilson, K.M., Dumont, E., Bonvoisin, B. \& Barrett, J. (2005) Monthly oral ibandronate is well tolerated and efficacious in postmenopausal women: results from the monthly oral pilot study. Journal of Clinical Endocrinology and Metabolism, 90, 5018-5024.

Reid, D.M. (2006) Once-monthly dosing: an effective step forward. Bone, 38, S18-S22.

Rogers, M.J. (2003) New insights into the molecular mechanisms of action of bisphosphonates. Current Pharmaceutical Design, 9, 2643-2658.

Rogers, M.J., Frith, J.C., Luckman, S.P., Coxon, F.P., Benford, H.L., Monkkonen, J., Auriola, S., Chilton, K.M. \& Russell, R.G. (1999) Molecular mechanisms of action of bisphosphonates. Bone, 24, 73S$79 S$.

Rowland, M. \& Tozer, T.N. (1995) Clinical Pharmacokinetics. Concepts and applications, 3rd edn. Lippincott Williams \& Wilkins, Philadelphia, PA.

Sato, M., Grasser, W., Endo, N., Akins, R., Simmons, H., Thompson, D.D., Golub, E. \& Rodan, G.A. (1991) Bisphosphonate action. Alendronate localization in rat bone and effects on osteoclast ultrastructure. Journal of Clinical Investigation, 88, 2095-2105.

Stashak, T.S. (1998) Examination for lameness. In Adam's Lameness in Horses, 5th edn. Ed Stashak, T.S., pp. 113-183. Lippincott Williams \& Wilkins, Philadelphia, PA.

Tanko, L.B., Mouritzen, U., Lehmann, H.J., Warming, L., Moelgaard, A., Christgau, S., Qvist, P., Baumann, M., Wieczorek, L., Hoyle, N. \& Christiansen, C. (2003) Oral ibandronate: changes in markers of bone turnover during adequately dosed continuous and weekly therapy and during different suboptimally dosed treatment regimens. Bone, 32, 687-693.

Tasker, J.B. (1966) Fluid and electrolyte studies in the horse. II. An apparatus for the collection of total daily urine and feces from horses. The Cornell Veterinarian, 56, 77-84.

Toutain, P.L. \& Koritz, G.D. (1997) Veterinary drug bioequivalence determination. Journal of Veterinary Pharmacology and Therapeutics, 20, 79-90.

Varela, A., Lepage, O.M., Doucet, M., Marcoux, M. \& Garnero, P. (2002) Tiludronate chez le cheval: tolérance et effets à court terme sur le métabolisme osseux. Annales de Médecine Vétérinaire, 147, 123-130.

Yun, M.H., Woo, J.S. \& Kwon, K.I. (2006) Bioequivalence and pharmacokinetics of $70 \mathrm{mg}$ alendronate sodium tablets by measuring alendronate in plasma. Archives of Pharmacal Research, 29, 328-332. 